\title{
Impact of vibrations on people residing in buildings from different types of traffic loads according to the VDV scale
}

\author{
Krzysztof Kozioł ${ }^{1, a}$ \\ ${ }^{1}$ Cracow University of Technology, Cracow, Warszawska 24 St., 31-155, Poland
}

\begin{abstract}
Development of communication lines as well as reducing the distance of its location from buildings contributes to the deterioration of human comfort residing in buildings. For that reason it is necessary to determine the size of this nuisance. This paper presents a comparative analysis in order to determine influence of vibrations originating from selected means of transport for people in buildings using ISO 2631-1, British BS 6472-1 and Polish pr PN/B-02171 standards. The analysis focuses mainly on the parameter called dose of vibrations - VDV. In the comparative analysis - as the load acting on the human - vibration acceleration of ceilings caused by crossing subway, truck, tram and train were used. Presented in the paper analysis show, that each types of considered traffic excitations gives similar results for all concerned standards. In case of BS648 standard values of VDV are smaller in vertical direction than for other standards. However, for extortions, in which in the amplitude-frequency characteristics dominate lower natural frequencies, difference between obtained results decreases.
\end{abstract}

\section{Introduction}

Comfort of the people staying in buildings is affected by floor deflections as well as its response in time, which can be caused by following factors:

- reaching the occupied space from outside causing the movement of the building foundations - it could be a seismic or so called paraseismic vibrations, transmitted from ground to building or vibrations transmitted through the outside barriers (walls) affecting changes in air pressure (eg. acoustic wave),

- generated in the building in which there is a room dedicated to people accommodation as well as generated by people - for example, walking in the room.

Considering the question of comfort people staying inside the rooms of existing building subjected to dynamic excitations we have to choose assessment criteria and determine the parameters describing them. It is quite obvious that for almost identical dynamic loads, analysis result of vibrations impact on people will be different for standards binding in different countries. However, there is a question about discrepancies between the different dynamic influences (eg movement of cars, trams, subway etc.) which are defined according to the same criteria but using different standards.

\section{Historical background}

At the beginning of the twentieth century (in 1931) the Reicher's and Meister's scales were published, which

\footnotetext{
${ }^{\mathrm{a}}$ Corresponding author: kkoziol@pk.edu.pl
}

are defining relationship between frequency of vibration and movement of the structure in the vertical direction (Fig. 1). These scales were prepared on the basis of the behavior of people subjected to stationary excitations. Therefore, they cannot be used for any kind of structure, in particular for the buildings with high damping, in which response to the generated vibration is non-stationary. Lenzen's [1] investigations concerning reinforced concrete and steel ceilings subjected to impact loads, as well as Murray's [2] studies including implementations for ceiling construction different types of steel; contributed to introduce proposals to reduce the applicability (due to the force type) of modification (due to frequency response of the object) the Reicher 's and Meister's scales.

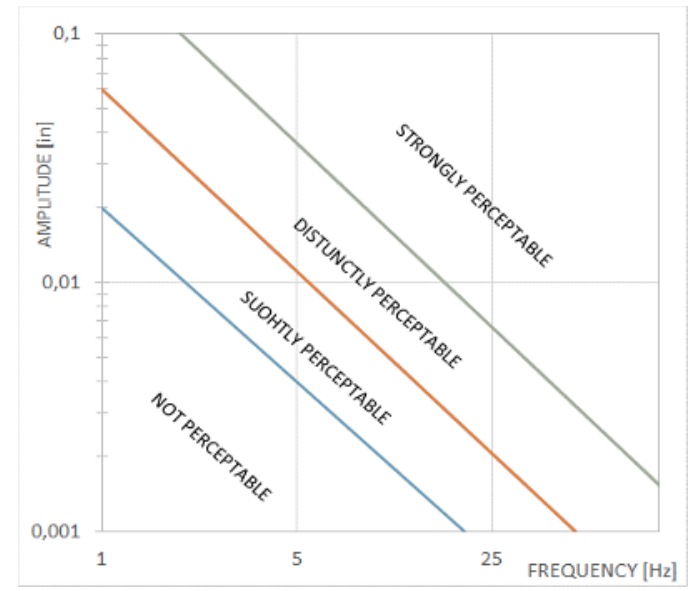

Figure 1 Reicher's and Meister's scale [7] 
In 1974 it was published McCormick work [3] concerning selection of the design criteria for the construction of floors. According to his research, damping is an important parameter determining about admission of ceiling for application in construction. In 1974, Wiss and Parmelee have developed experimental five-level scale (from harmless to harmful) connecting vibrations of the floor and evaluation of its response for human. In 1974 also appeared first edition of ISO standard concerning the human response to vibration of the floor. These guidelines are result of research carried out by Crowley. This standard through the work of Irwin (1978) has been modified and published in 1985 under the ISO 2631name. On its basis guidelines of standards are prepared for many regions, in particular British BS 6481 and Polish pr-PN / B-02171.

\section{Assumptions}

Standards: ISO 2631-2 [4], BS 6472-1 [5] British and Polish pr PN/B-02171 [6] introduces following factors assessing the impact of vibration on human:

- purpose of the room in building,

- part of the day, in which vibrations occur,

- nature of vibrations and their repeatability,

- direction of vibrations and position of human body while receiving vibrations.

During evaluation of impact of vibrations on people in buildings, it is essential to select proper criteria and related to it assessment methods and parameters, which include:

- acceleration (velocity, displacement) during vibrations (in considered frequency range),

- amplitude-frequency spectrum of acceleration (velocity, displacement), in particular the effective value of vibrations (RMS) in 1/3 octave band,

- vibration dose value (VDV),

- Maximum Transfer Value of the vibrations transition (MTV).

According to ISO 2631, BS 6472-1 British and Polish prPN/B-02171 as a basic evaluation parameter it is assumed analysis of effective response of structure RMS. However, in justified cases, it is recommended to use additional methods: VDV and MTV. These situations include cases, in which the peak factor during analyzed measurements is greater than 6 . As the event time one should take time interval in which the beginning and end value reaches $20 \%$ of the extreme amplitude of measured parameter (in this case - acceleration).

Peak factor "As" (equation 2) is defined as ratio of the absolute value within extreme values of measured parameters to mean value (RMS-equation 1) of this parameter during measuring time.

$$
\operatorname{RMS}:=\left(\frac{\int_{0}^{\mathrm{T}} \mathrm{a}_{\mathrm{w}}(\mathrm{t})^{2} \mathrm{dt}}{\mathrm{T}}\right)^{0.5}
$$

$$
\mathrm{A}_{\mathrm{S}}:=\frac{\mathrm{A}_{\max }}{\mathrm{RMS}}
$$

where: $a_{w}(t)-$ is weighted acceleration as a function of time $[\mathrm{m} / \mathrm{s} 2]$;

$\mathrm{T}-$ is the duration of measurement [s],

$\mathrm{A}_{\max }$ - extreme acceleration amplitude

VDV (equation 2) parameter is called Vibration Dose Value and is defined by following relationship:

$$
V D V=\left[\int_{0}^{T} a_{w}^{4}(t) d t\right]^{\frac{1}{4}}
$$

It should be noted that for acceleration $\mathrm{a}_{\mathrm{w}}(\mathrm{t})$ it is imposed filter, which is visualized in Fig. 2. and table 1

Table 1. Weighting values for accelerations of the vertical (zaxis) and horizontal (x,y-axis) directions in a 1/3-octave band spectrum $1-80 \mathrm{~Hz}$

\begin{tabular}{|c|c|c|c|c|c|c|}
\hline \multirow{2}{*}{$\begin{array}{c}\text { RMS } \\
\text { ferguency }\end{array}$} & \multicolumn{2}{|c|}{$\begin{array}{c}\text { ISO } 2631, \\
\text { prPN/B02171 }\end{array}$} & \multicolumn{2}{c|}{ BS $6481-1$} & \multicolumn{2}{c|}{$\%$ average } \\
\cline { 2 - 7 } & Vertical & Horizontal & Vertical & Horizontal & Vertical & Horizontal \\
\hline$[\mathrm{Hz}]$ & {$[-]$} & & {$[-]$} & & {$[\%]$} & {$[\%]$} \\
\hline 1,00 & 0,482 & 1,011 & 0,500 & 1,000 & $-4 \%$ & $1 \%$ \\
\hline 1,25 & 0,484 & 1,008 & 0,559 & 1,000 & $-13 \%$ & $1 \%$ \\
\hline 1,60 & 0,494 & 0,968 & 0,632 & 1,000 & $-22 \%$ & $-3 \%$ \\
\hline 2,00 & 0,531 & 0,890 & 0,707 & 1,000 & $-25 \%$ & $-11 \%$ \\
\hline 2,50 & 0,631 & 0,776 & 0,791 & 0,800 & $-20 \%$ & $-3 \%$ \\
\hline 3,15 & 0,804 & 0,642 & 0,887 & 0,635 & $-9 \%$ & $1 \%$ \\
\hline 4,00 & 0,967 & 0,512 & 1,000 & 0,500 & $-3 \%$ & $2 \%$ \\
\hline 5,00 & 1,039 & 0,409 & 1,000 & 0,400 & $4 \%$ & $2 \%$ \\
\hline 6,30 & 1,054 & 0,323 & 1,000 & 0,317 & $5 \%$ & $2 \%$ \\
\hline 8,00 & 1,036 & 0,253 & 1,000 & 0,250 & $4 \%$ & $1 \%$ \\
\hline 10,00 & 0,988 & 0,212 & 0,800 & 0,200 & $24 \%$ & $6 \%$ \\
\hline 12,50 & 0,902 & 0,161 & 0,640 & 0,160 & $41 \%$ & $1 \%$ \\
\hline 16,00 & 0,768 & 0,125 & 0,500 & 0,125 & $54 \%$ & $0 \%$ \\
\hline 20,00 & 0,636 & 0,100 & 0,400 & 0,100 & $59 \%$ & $0 \%$ \\
\hline 25,00 & 0,513 & 0,080 & 0,320 & 0,080 & $60 \%$ & $0 \%$ \\
\hline 31,50 & 0,405 & 0,063 & 0,254 & 0,063 & $59 \%$ & $0 \%$ \\
\hline 40,00 & 0,314 & 0,049 & 0,200 & 0,050 & $57 \%$ & $-1 \%$ \\
\hline 50,00 & 0,246 & 0,039 & 0,160 & 0,040 & $54 \%$ & $-3 \%$ \\
\hline 63,00 & 0,186 & 0,030 & 0,127 & 0,032 & $46 \%$ & $-8 \%$ \\
\hline 80,00 & 0,132 & 0,021 & 0,100 & 0,025 & $32 \%$ & $-16 \%$ \\
\hline & & & & & & \\
\hline
\end{tabular}

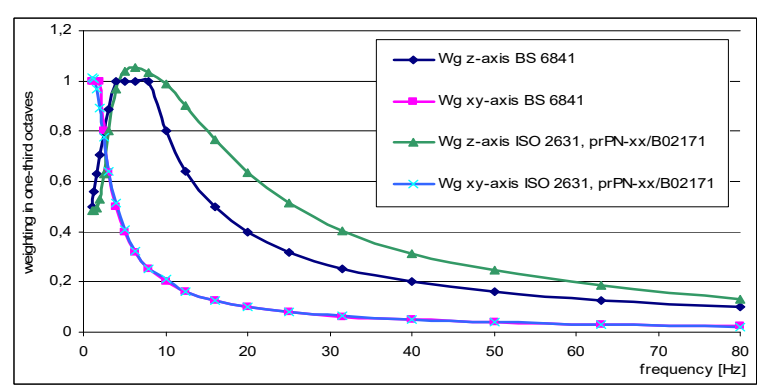

Figure 2 A graph of weight filter for acceleration in horizontal and vertical directions for ISO2631, British BS 6481 and BS Polish pr-PN/B-02171 standard.

As is clear from figure 2 and table 1 weight factors for the ISO 2631 and Polish pr PN-8xx / B-02171 are the same regardless of the direction of vibration. In case of horizontal direction for each of mentioned standards weight coefficients of filters are similar. The aim of the study is to show differences between values of the 
same parameter (here VDV) obtained using different standards.

If the vibration exposure is comprised of two or more events "i" which are characterized by $\mathrm{VDV}_{\mathrm{i}}$ values, and during day or night occurred $\mathrm{N}$ events that characterize the $\mathrm{VDV}_{\mathrm{i}}$, therefore total value of dose vibration VDV could be determined from formula (4):

$$
V D V=\left[\sum\left(V D V_{i}\right)^{4}\right]^{0,25}
$$

According BS 6472-1 (Table 2) is a low probability of adverse comment or disturbance to building occupants at vibration values below the preferred values. Complaints may be expected if vibration values approach the maximum values. Activities should be designed to meet the preferred values where an area is not already exposed to vibration.

Table 2. Acceptable vibration dose values for intermittent vibrations $\left[\mathrm{m} / \mathrm{s}^{1.75}\right]-[5]$

\begin{tabular}{|c|c|c|c|c|}
\hline \multirow{2}{*}{ Locafon } & \multicolumn{2}{|c|}{ Dayime (7.00am to $10.00 \mathrm{pm})$} & \multicolumn{2}{|c|}{ Night:-fme (10.00pm to $7.00 \mathrm{am})$} \\
\hline & Preferred value & Maximum value & Preferred value & Maximum value \\
\hline Crifical areas1 & 0.10 & 0.20 & 0.10 & 0.20 \\
\hline Residences & 0.20 & 0.40 & 0.13 & 0.26 \\
\hline $\begin{array}{l}\text { Offces, schools, educational } \\
\text { instiffons and places of } \\
\text { worship }\end{array}$ & 0.40 & 0.80 & 0.40 & 0.80 \\
\hline Workshops & 0.80 & 1.60 & 0.80 & 1.60 \\
\hline
\end{tabular}

\section{Analysis}

The paper analyses the VDV factor for vibration accelerations recorded on ceilings for real objects. These accelerations are caused by moving cars, trams, subway a and trains (Fig. 3).
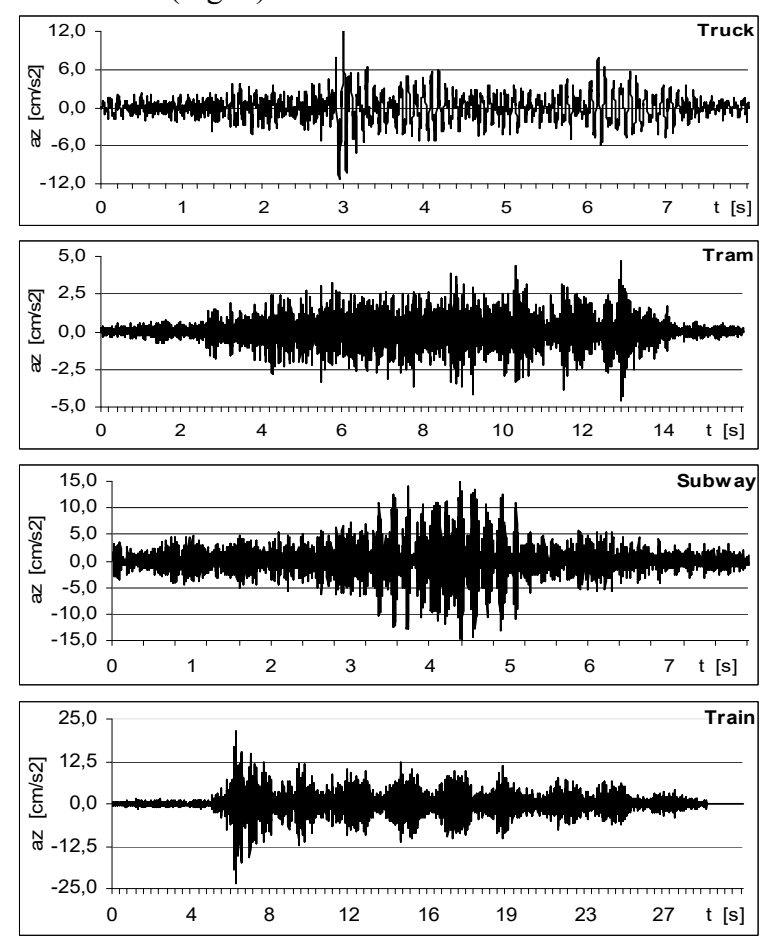

Figure 3 Plot of vertical accelerations of vibrations of the floor caused by the movement of truck, tram, subway and train.
These are vertical components of ceiling vibration acceleration (unweighted) registered on real buildings. Car and subway as well as tram movements are associated with the same building.

As is apparent from the performed amplitudefrequency analysis (Figure 4) the ceiling responses caused by moving truck are dominated by the frequency of 8 to 12 $\mathrm{Hz}$, for which the weight factor of vibration acceleration varies in the range of 1.036 to 0.902 for the ISO standard and from 1.00 to 0.640 for BS standard (Table 1)

Influence of the floor acceleration amplitudes in the other frequency bands is negligible. Considering the fact that in the dominant frequency range of excitation associated with passing car, differences between the ISO and BS standards are lowest - ranging from $4 \%$ to $24 \%$ (Table 1), discrepancy in the VDV ratio are equal to $27 \%$ - Table. 3 . Other structure responses are characterized by vibrations amplitudes components with higher frequencies.

- for tram - dominant component of acceleration amplitudes are focused around a frequency of $20 \mathrm{~Hz}$,

- for subway one can observe in floor responses accelerations with frequencies ranging from $40 \mathrm{~Hz}$ to $80 \mathrm{~Hz}$, and the largest accelerations amplitudes have frequencies around $55 \mathrm{~Hz}$,

- influence of train is characterized by floor accelerations with frequencies above $30 \mathrm{~Hz}$ and dominant frequency is $45 \mathrm{~Hz}$.

While above the frequency $16 \mathrm{~Hz}$ the ratio of the weighting factor applied to the acceleration proposed in ISO standard
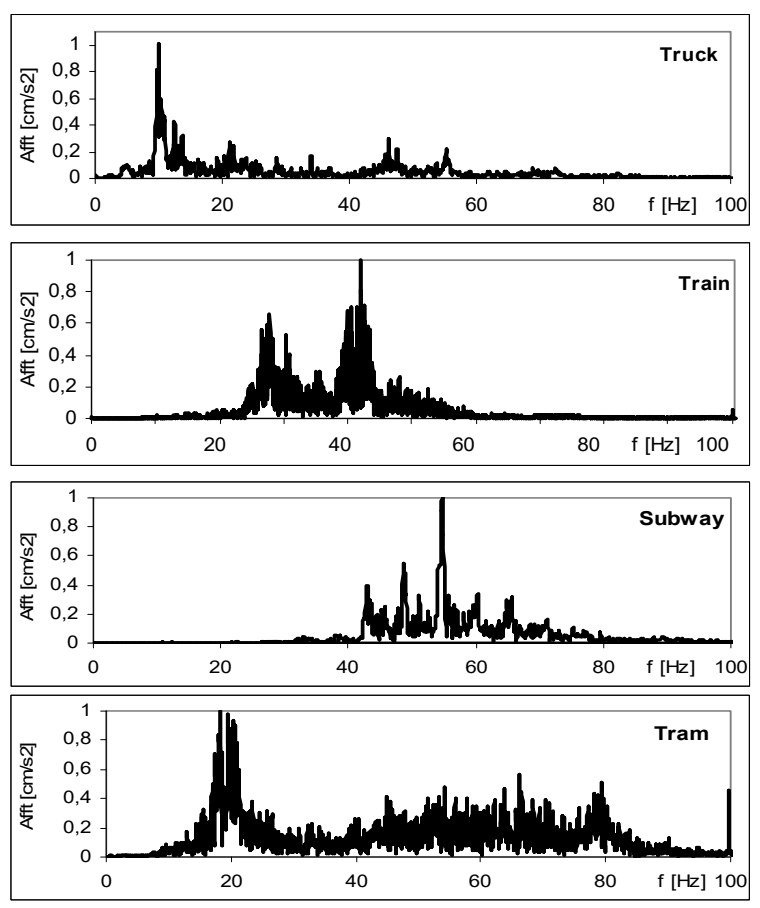

Figure 4. Amplitude-frequency analysis of excitations coming from car, tram, subway and train traffic

to its counterpart applied in the BS standard is more than $50 \%$ (with a slight reduction to the $32 \%$ at a frequency of $80 \mathrm{~Hz}$ ) afforded the difference between VDV for excitations which generate vibrations with frequencies greater than $16 \mathrm{~Hz}$ at a similar level (from $52 \%$ to $58 \%$ ) Table. 3. The peak factors for analyzed acceleration 
waveforms (non-weighted) are respectively 12.34 for cars, 6.02 for trams, 15.9 for subway and 22.1 for trains. Applying of the weight factors for accelerations in the present case was the cause of a reduction in the peak factor:

- for ISO standard $28.7 \%$ in case of cars, $75.8 \%$ for subway, $44.8 \%$ for trams and $36.4 \%$ for trains,

- for BS standard $46.4 \%$ in case of cars, $84.1 \%$ for subway, $64.8 \%$ for trams and $77 \%$ for trains.

Such a large reduction of peak coefficients after weighing stems from the fact of wide spectrum of acceleration and a small difference between the dominant signal amplitudes and other amplitudes. In the case of car movements the dominant amplitude of the ceiling response expressly dominates over the other, and the frequency spectrum is very narrow therefore weighting the signal has a very small impact on change of the event time (signal duration) and the change in amplitude is close to its simple rescaling.

Table 3. Analyzes results

\begin{tabular}{|c|c|c|c|c|c|c|c|c|}
\hline \multirow[b]{2}{*}{ 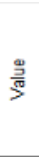 } & \multirow[b]{2}{*}{ 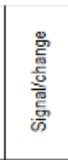 } & \multirow[b]{2}{*}{ 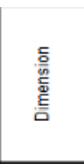 } & \multicolumn{3}{|c|}{ Tram } & \multicolumn{3}{|c|}{ Train } \\
\hline & & & 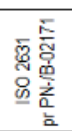 & 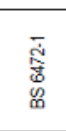 & 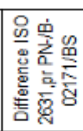 & 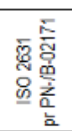 & $\begin{array}{l}\overline{\tilde{N}} \\
\text { 今̊ } \\
\stackrel{\infty}{\infty}\end{array}$ & 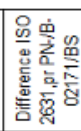 \\
\hline \multirow{3}{*}{$\sum_{x}^{\infty}$} & $a$ & {$\left[\mathrm{~cm} / \mathrm{s}^{2}\right]$} & \multicolumn{2}{|c|}{0.63} & . & \multicolumn{2}{|c|}{2,70} & . \\
\hline & $a_{w}$ & {$\left[\mathrm{~cm} / \mathrm{s}^{2}\right]$} & 0,30 & 0,19 & \multirow{2}{*}{$55,8 \%$} & 0,96 & 0.61 & \multirow{2}{*}{$58.1 \%$} \\
\hline & change & {$[\%]$} & $52,2 \%$ & $69,3 \%$ & & $64,4 \%$ & $77,4 \%$ & \\
\hline \multirow{3}{*}{ 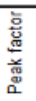 } & $a$ & {$\left[\mathrm{~cm} / \mathrm{s}^{2}\right]$} & \multicolumn{2}{|c|}{6.02} & 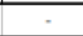 & \multicolumn{2}{|c|}{21.22} & \multirow{3}{*}{$58.1 \%$} \\
\hline & $a_{w}$ & {$\left[\mathrm{~cm} / \mathrm{s}^{2}\right]$} & 2,58 & 1,65 & \multirow{2}{*}{$56,7 \%$} & 7,73 & 4,89 & \\
\hline & change & {$[\%]$} & $57,2 \%$ & $72,7 \%$ & & $36,4 \%$ & $77,0 \%$ & \\
\hline & $\mathrm{a}$ & {$\left[\mathrm{cm} / \mathrm{s}^{1,75}\right.$} & \multicolumn{2}{|c|}{2,67} & - & \multicolumn{2}{|c|}{10.99} & \multirow{3}{*}{$58.2 \%$} \\
\hline \multirow{3}{*}{ ऐे } & $a_{w}$ & {$\left[\mathrm{~cm} / \mathrm{s}^{1,700}\right]$} & 1,39 & 0.89 & \multirow{2}{*}{$56.5 \%$} & 3,97 & 2.51 & \\
\hline & \begin{tabular}{|l} 
change \\
\end{tabular} & {$[\%]$} & $47,9 \%$ & $66,7 \%$ & & $36,1 \%$ & $77,2 \%$ & \\
\hline & daytime & {$\left[\mathrm{cm} / \mathrm{s}^{1,75}\right.$} & 5,79 & 3,70 & - & 11,05 & 6,99 & \\
\hline \multirow[b]{2}{*}{ 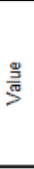 } & \multirow[b]{2}{*}{ 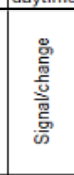 } & \multirow[b]{2}{*}{ 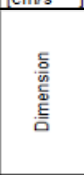 } & \multicolumn{3}{|c|}{ Truck } & \multicolumn{3}{|c|}{ Subway } \\
\hline & & & 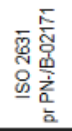 & 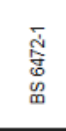 & 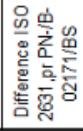 & 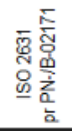 & 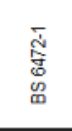 & 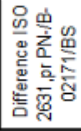 \\
\hline \multirow{3}{*}{$\sum_{x}^{\infty}$} & $a$ & {$\left[\mathrm{~cm} / \mathrm{s}^{2}\right]$} & \multicolumn{2}{|c|}{1,44} & - & \multicolumn{2}{|c|}{1,61} & - \\
\hline & $a_{w}$ & {$\left[\mathrm{~cm} / \mathrm{s}^{2}\right]$} & 1,22 & 0,96 & 2609 & 0,37 & 0,24 & $51.9 \%$ \\
\hline & change & {$[\%]$} & $15.4 \%$ & $33,3 \%$ & & $77.0 \%$ & $84.9 \%$ & (1, \\
\hline 홈 & $a$ & {$\left[\mathrm{~cm} / \mathrm{s}^{2}\right]$} & & & - & & & - \\
\hline & $a_{w}$ & {$\left[\mathrm{~cm} / \mathrm{s}^{2}\right]$} & 8.80 & 6.62 & 3009 & 3,85 & 2.52 & $527 \%$ \\
\hline & change & {$[\%]$} & $28,7 \%$ & $46,4 \%$ & & $75,8 \%$ & $84,1 \%$ & $52,7 \%$ \\
\hline & $a$ & {$\left[\mathrm{~cm} / \mathrm{s}^{1,75]}\right.$} & & & - & & & - \\
\hline हो & $a_{w}$ & {$\left[\mathrm{~cm} / \mathrm{s}^{1,75}\right]$} & 4,40 & 3,46 & & 1,96 & 1,29 & 50 \\
\hline & change & {$[\%]$} & $16.6 \%$ & $34,4 \%$ & $27,2 \%$ & $77,0 \%$ & $84.9 \%$ & $52,0 \%$ \\
\hline & daytime & {$\left[\mathrm{cm} / \mathrm{s}^{1,75}\right.$} & 18,32 & 14,40 & & 8,14 & 5.35 & \\
\hline
\end{tabular}

Table. 3 shows daily values of VDV (daytime) coefficients. It was assumed 300 passages of trams, subways and cars as well as 60 train passages. As we can see in each of the analyzed cases there is low probability of occurrence of complaints residents because the rooms in which the measured acceleration have residential destination.

\section{Conclusion}

Estimation of vibration harmfulness felt by people in buildings using VDV ratio according to ISO2631 and estimated in accordance with standards binding in various countries (eg PN, BS) does not lead to convergent results. The reason for this are the different weighting functions imposed on the measured acceleration (Fig. 2). Due to the non-linear relationship between weighting function imposed on the amplitude and frequency of their prevalence, resulting from the analysis VDV values are a function of the spectral distribution of the recorded acceleration. Due to the fact that the recorded ceilings responses (resulting from car, tram, metro and train passages) acceleration amplitude at frequencies below $5 \mathrm{~Hz}$ are negligible (less than $0.5 \%$ ) and VDV ratios calculated according ISO standard are greater than if they were calculated according BS standard. The smallest differences between the analyzed standards are achieved for the passage of the car. This is due to the smallest differences in the weighting functions applied to the amplitudes occurring in the dominant frequency response of the structure. The differences in the VDV values (for the tram, train and subway) obtained in accordance with ISO and BS are at 52\% -58\% and are due to differences (from $46 \%$ to $60 \%$ ) between the weighting factors for the acceleration amplitudes of the dominant frequencies present in the signal.

So without any information about the amplitude-frequency structure of response, referencing VDVs obtained in accordance with various standards to the vibrations perceptibility threshold can cause errors.

According to pr PN/B-02171 standard, analysis using the VDV is treated as informational used to assess complaints of inhabitants. Author proposes usage of weighting coefficients for the acceleration in accordance with ISO, and the threshold values compatible with the BS. This means greater than in BSstandard probability of residents complaints due to traffic loads.

\section{References}

1. Lenzen, K. H., "Vibration of Steel Joist-Concrete Slab Floors," Engineering Journal, American Institute of Steel Construction, 3rd Qtr., pp. 133136, 1966.

2. Murray, T. M., "Design to Prevent Floor Vibrations," Engineering Journal, American Institute of Steel Construction, 3rd Qtr., pp. 8287, 1975.

3. McCormick, M. M., Office Floor Vibration: Design Criteria and Tests, Melbourne Research Laboratories, The Broken Hill Proprietary Company Lmt.f Melbourne, Australia, 1974.

4. ISO 2631-1, Mechanical vibration and shock ewaluation of human exposure to whole-body vibration Part 1 General requirements 1997 International Organization for Standardization.

5. BS 6472-1:2008, Guide to evaluation of human exposure to vibration in buildings, Part 1: Vibration sources other than blasting, 2008,

6. Pr PN/B-02171, Evaluation of vibrations influence on people in buildings

7. Lara, K.M, Ricadro, C. "Parametric study on the vibration sensitivity of hollow-core slab floors" Eurodyn 2014 